\title{
Degradation of resin-dentin bonds of etch-and-rinse adhesive system to primary and permanent teeth
}

\section{Tathiane Larissa Lenzi(a) Fabio Zovico Maxnuck Soares ${ }^{(b)}$ Rachel de Oliveira Rocha ${ }^{(c)}$}

\footnotetext{
(a) Department of Orthodontics and Pediatric Dentistry, School of Dentistry, Univ of São Paulo, São Paulo, SP, Brazil.

(b) Department of Restorative Dentistry, School of Dentistry, Univ Federal of Santa Maria, Santa Maria, RS, Brazil.

(c) Department of Stomatology, School of Dentistry, Univ Federal of Santa Maria, Santa Maria, RS, Brazil.
}

\begin{abstract}
The aim of this in vitro study was to compare the degradation of resin-dentin bonds of an etch-and-rinse adhesive system to primary and permanent teeth. Flat superficial coronal dentin surfaces from 5 primary second molars and 5 permanent third molars were etched with phosphoric acid and bonded with an adhesive system (Adper Single Bond 2, 3M ESPE). Blocks of resin composite (Z250, 3M ESPE) were built up and the teeth sectioned to produce bonded sticks with a $0.8 \mathrm{~mm}^{2}$ crosssectional area. The sticks of each tooth were randomly divided and assigned to be subjected to microtensile testing immediately $(24 \mathrm{~h})$ or after aging by water storage (6 months). Data were analyzed by two-way repeated measures ANOVA and Tukey post hoc test $(\alpha=0.05)$. Failure mode was evaluated using a stereomicroscope $(400 \times)$. Microtensile values significantly decreased after the 6 months aging, independent of the dentin substrate. In $24 \mathrm{~h}$, the values obtained to primary dentin were lower compared with permanent dentin. This difference was not maintained after aging. Adhesive/mixed failure was predominant in all experimental groups. In conclusion, degradation of resin-dentin bonds of the etch-and-rinse adhesive system occurred after 6 months of water storage; however, the reduction in bond strength values was higher for permanent teeth.
\end{abstract}

Descriptors: Dentin; Longevity; Tensile Strength; Tooth, Deciduous; Dentition, Permanent.

\section{Introduction}

Traditionally, knowledge acquired in laboratory or in vivo studies using permanent teeth has been extrapolated to primary teeth, since the same bonding protocol is indicated for both substrates, despite chemical and micromorphological differences. ${ }^{1,2}$

It has been reported that the hybrid layers produced in primary teeth were approximately $25 \%-30 \%$ thicker than those produced in permanent dentin using identical acid etching time. This indicates that primary dentin is more reactive to acid etching due to the lower mineral content. ${ }^{3,4}$ Consequently, the lack of complete infiltration of adhesive resin into previously demineralized dentin creates a zone more prone to degradation, ${ }^{5}$ which may be more pronounced in primary dentin.

Although several studies have evaluated the immediate bond strength of simplified adhesive systems to permanent and primary dentin, the re-
Submitted: Apr 18, 2012

Accepted for publication: Jul 28, 2012

Last revision: Jul 31, 2012 
sults obtained are still controversial. While some studies have shown lower bond strength in primary dentin, ${ }^{6,7}$ others have found similar ${ }^{8-10}$ or even superior performance of the adhesive systems in primary dentin. ${ }^{11}$ Moreover, to the best of our knowledge, this is a pioneering investigation that has evaluated long-term performance of etch-and-rinse adhesive system to permanent and primary dentin.

Therefore, this in vitro study aimed to compare the degradation of resin-dentin bonds of an etchand-rinse adhesive system to primary and permanent teeth.

\section{Methodology \\ Tooth selection and preparation}

Ten sound human teeth, consisting of 5 primary second molars and 5 permanent third molars were collected after the patients' informed consent had been obtained under a protocol reviewed and approved by the Institutional Ethics Board. The teeth were disinfected in $0.5 \%$ aqueous chloramine and stored in distilled water at $4^{\circ} \mathrm{C}$ until use.

The occlusal enamel was removed with a watercooled diamond saw in a cutting machine (Labcut 1010, Extec Co., Enfield, USA) to obtain flat dentin surfaces. The surrounding enamel was also removed with a diamond bur (\# 3195, KG Sorensen, Barueri, Brazil) in a high-speed handpiece with water spray. The specimens were carefully examined under a stereomicroscope at $30 \times$ magnification to confirm the absence of enamel islets. The exposed occlusal dentin surfaces were then polished with 600-grit silicon carbide abrasive paper under running water for $30 \mathrm{~s}$ to obtain a uniform and standardized smear layer.

\section{Bonding procedures}

In both the primary and permanent teeth, the dentin surfaces were etched with $35 \%$ phosphoric acid gel (Scotchbond, 3M ESPE, St. Paul, USA) for $15 \mathrm{~s}$, rinsed with water and gently blotted with absorbent paper to keep a moist surface. Two consecutive coats of the adhesive system (Adper Single Bond 2, 3M ESPE, St. Paul, USA) were applied, gently air dried, and light-cured for $10 \mathrm{~s}$. Resin composite (Filtek Z250, 3M ESPE, St. Paul, USA) was built up on the bonded surfaces in increments of approxi- mately $1.5 \mathrm{~mm}$, and individually light-cured for $20 \mathrm{~s}$ (Led Olsen, Olsen Ind. e Com. S/A, Palhoça, Brazil), at $800 \mathrm{~mW} / \mathrm{cm}^{2}$. All specimens were stored in distilled water at $37^{\circ} \mathrm{C}$ for $24 \mathrm{~h}$.

\section{Microtensile bond strength ( $\mu \mathrm{TBS}$ )}

Specimens were serially sectioned longitudinally through the bond interface with a water-cooled diamond saw in a cutting machine (Labcut 1010, Extec Co., Enfield, USA) in order to obtain sticks with a cross-sectional area of approximately $0.8 \mathrm{~mm}^{2}$, according to the microtensile "non-trimming" technique. The cross-sectional area of each stick was measured with a digital caliper (Absolute Digimatic, Mitutoyo, Tokyo, Japan) for calculating bond strength. The sticks were carefully examined with a stereomicroscope at $30 \times$ magnification and those with defects at the resin-dentin interface were discarded.

The bonded sticks originating from the same teeth were randomly subdivided into 2 groups, according to storage time:

- immediately or

- for 6 months (in distilled water containing $0.4 \%$ sodium azide at $37^{\circ} \mathrm{C}$ ).

The storage solution was not changed and its $\mathrm{pH}$ was monitored monthly. After each storage period, the bonded sticks were attached to a device for microtensile testing with cyanoacrylate resin and subjected to the microtensile test on a universal testing machine (DL 2000, Emic, São José dos Pinhais, Brazil) at a crosshead speed of $1 \mathrm{~mm} / \mathrm{min}$.

\section{Failure mode}

All debonded sticks were observed in a stereomicroscope (HMV II, Shimadzu, Kyoto, Japan) at $400 \times$ magnification to determine failure mode:

- adhesive/mixed (failure at the resin-dentin interface or mixed with cohesive failure of the neighboring substrate) or

- cohesive (failure exclusively within the dentin or resin composite).

\section{Statistical analysis}

The experimental unit in this study was the he- 
mi-tooth, since half the sample was tested immediately and the other half was tested after 6 months. Thus, means of the microtensile bond strength $(\mathrm{MPa})$ of all sticks from the same hemi-tooth was averaged for statistical purposes. The microtensile bond strength means for every testing group was expressed as the average of the 5 teeth used per group.

Normal distribution of data was confirmed using the Kolmogorov-Smirnov test. Data obtained were analyzed with two-way repeated measures ANOVA using a factorial design with substrate (primary or permanent dentin) and storage time $(24 \mathrm{~h}$ or 6 months) as variables. Tukey's HSD multiple comparisons statistical test at a 0.05 significance level was used. Failure mode was only qualitatively evaluated.

\section{Results}

Microtensile bond strength means $(\mathrm{MPa})$ and standard deviations for all experimental groups are displayed in Table 1 . The main factors dentin substrate $(p=0.000)$ and storage time $(p=0.000)$, as well as, cross-product interaction $(p=0.008)$ were statistically significant.

The $\mu$ TBS values significantly decreased after 6 months of water storage, regardless of dentin substrate (around $20.5 \%$ to $32.1 \%$ for primary and

Table 1 - Microtensile bond strength means (MPa) and standard deviations for all experimental groups.

\begin{tabular}{c|c|c}
\hline \multirow{2}{*}{$\begin{array}{c}\text { Dentin } \\
\text { substrate }\end{array}$} & \multicolumn{2}{|c}{ Storage time } \\
\cline { 2 - 3 } & Immediate & 6 months \\
\hline Primary & $30.7 \pm 2.2^{\mathrm{B}}$ & $24.4 \pm 3.8^{\mathrm{C}}$ \\
\hline Permanent & $41.7 \pm 2.7^{\mathrm{A}}$ & $28.3 \pm 3.0^{\mathrm{B}, \mathrm{C}}$ \\
\hline
\end{tabular}

Different letters indicate statistically significant difference $(p<0.05)$. permanent teeth, respectively). In the immediate evaluation, values obtained for primary dentin were lower than those of permanent dentin. This difference was not maintained after aging.

Distribution of the failure mode is summarized in Table 2. For all groups, adhesive/mixed failure prevailed.

\section{Discussion}

There is no consensus in the literature concerning the bonding of adhesive systems to primary and permanent dentin. ${ }^{6-11}$ Based on the outcomes of the current study it can be stated that the immediate bond strength of the etch-and-rinse adhesive is higher in permanent dentin compared with primary dentin, using the same bonding protocol. This finding is in agreement with previous studies. . $^{6,712,13}$

Differences in the percentage of mineral components, tubular diameter and density and intrinsic moisture of primary and permanent teeth may influence adhesive performance, resulting in lower $\mu \mathrm{TBS}$ for primary dentin. While greater density of the tubules and larger diameter ${ }^{1}$ result in a reduced area of intertubular dentin available for bonding, the lower mineral content ${ }^{2}$ reduce the buffering capacity and increase the reactivity of primary dentin to acidic solutions, resulting in the formation of thicker hybrid layers compared with permanent teeth. ${ }^{3,4}$

Prolonged etching time tend to produce deeper dentin demineralization, ${ }^{5}$ and subsequently, a nonimpregnated area along the bottom of the hybrid layer that containing exposed collagen fibrils, more prone to undergo enzymatic ${ }^{14}$ and hydrolytic ${ }^{15-17}$ degradation over time. Even though several researches have assessed the deterioration of resindentin bonds in permanent teeth, information re-

Table 2 - Number and percentage of sticks (\%) and total of sticks tested according to failure mode and premature failures for all experimental groups.

\begin{tabular}{c|c|c|c|c|c|c|c|c|c|c}
\hline Storage time & \multicolumn{9}{|c|}{ Immediate } & \multicolumn{4}{c}{6 months } \\
\hline Failure mode & $\mathrm{A} / \mathrm{M}$ & $\mathrm{CD}$ & $\mathrm{CR}$ & Premature & Total & $\mathrm{A} / \mathrm{M}$ & $\mathrm{CD}$ & $\mathrm{CR}$ & Premature & Total \\
\hline Primary & $29(76.3 \%)$ & $4(10.5 \%)$ & $5(13.2 \%)$ & $0(0 \%)$ & 38 & $21(56.8 \%)$ & $6(16.2 \%)$ & $9(24.3 \%)$ & $1(2.7 \%)$ & 37 \\
\hline Permanent & $24(70.6 \%)$ & $9(26.5 \%)$ & $1(2.9 \%)$ & $0(0 \%)$ & 34 & $19(52.8 \%)$ & $9(25 \%)$ & $7(19.4 \%)$ & $1(2.8 \%)$ & 36 \\
\hline
\end{tabular}

A/M: adhesive/mixed failure; CD: cohesive failure in dentin; CR: cohesive failure in resin; Premature failures: pre-testing failures due to specimens preparation or water storage time. 
garding their bonding stability to primary dentin is still limited. ${ }^{15,18-20}$

In fact, degradation of resin-dentin bonds was observed in the current study, represented by a decrease in $\mu$ TBS values after 6 months of water storage, as observed in previous studies. ${ }^{20,21}$ However, the reduction in bond strength was more pronounced for permanent dentin. Consequently, the difference observed in immediate $\mu$ TBS values between permanent and primary dentin was not maintained after aging in water.

Although a greater degradation in resin-primary dentin bonds was expected, this result seems to confirm that a direct relationship does not appear to exist between bond strength and hybrid layer thickness, ${ }^{5,22}$ even though this variable was not evaluated in the current study. More relevant than hybrid layer thickness is its favorable and uniform interaction with the substrate. ${ }^{9}$ Another hypothesis for the minor reduction in $\mu \mathrm{TBS}$ values might be related to the lower values obtained immediately and not to a lower susceptibility to degradation.

\section{References}

1. Sumikawa DA, Marshall GW, Gee L, Marshall SJ. Microstructure of primary tooth dentin. Pediatr Dent. 1999 NovDec;21(7):439-44.

2. Angker L, Nockolds C, Swain MV, Kilpatrick N. Quantitative analysis of the mineral content of sound and carious primary dentine using BSE imaging. Arch Oral Biol. 2004 Feb;49(2):99-107.

3. Nor JE, Feigal RJ, Dennison JB, Edwards CA. Dentin bonding: SEM comparison of the resin-dentin interface in primary and permanent teeth. J Dent Res. 1996 Jun;75(6):1396-403.

4. Nor JE, Feigal RJ, Dennison JB, Edwards CA. Dentin bonding: SEM comparison of the dentin surface in primary and permanent teeth. Pediatr Dent. 1997 May-Jun;19(4):246-52.

5. Hashimoto M, Ohno H, Endo K, Kaga M, Sano H, Oguchi $H$. The effect of hybrid layer thickness on bond strength: demineralized dentin zone of the hybrid layer. Dent Mater. 2000 Nov;16(6):406-11.

6. Uekusa S, Yamaguchi K, Miyazaki M, Tsubota K, Kurokawa $\mathrm{H}$, Hosoya $\mathrm{Y}$. Bonding efficacy of single-step self-etch systems to sound primary and permanent tooth dentin. Oper Dent. 2006 Sep-Oct;31(5):569-76.

7. Senawongse P, Harnirattisai C, Shimada Y, Tagami J. Effective bond strength of current adhesive systems on deciduous and permanent dentin. Oper Dent. 2004 Mar-Apr;29(2):196-202.
Thus, shortening the acid etching time of dentin has been considered in order to improve the immediate bond strength and, subsequently, the longevity of adhesive interfaces produced in primary teeth..$^{22,23}$ Likewise, the use of metalloproteinase inhibitors, as chlorhexidine digluconate, does not negatively influence the immediate bond strength and prevents, or least decelerates the deterioration of resin-dentin bonds in primary ${ }^{19,20}$ and permanent teeth..$^{24,25}$

Since only one property of the adhesive systems was evaluated in the current study, further researches evaluating other bonding properties and different adhesive bonding approaches should be conducted to elucidate the durability of resin-dentin interfaces in primary teeth.

\section{Conclusion}

Degradation of resin-dentin bonds of the etchand-rinse adhesive system occurred after 6 months of water storage; however, the reduction in bond strength values was higher for permanent teeth.

8. Ricci HA, Sanabe ME, Costa CA, Hebling J. Bond strength of two-step etch-and-rinse adhesive systems to the dentin of primary and permanent teeth. J Clin Pediatr Dent. 2010 Winter;35(2):163-8.

9. Soares FZ, Rocha RO, Raggio DP, Sadek FT, Cardoso PE. Microtensile bond strength of different adhesive systems to primary and permanent dentin. Pediatr Dent. 2005 NovDec;27(6):457-62.

10. Burrow MF, Nopnakeepong U, Phrukkanon S. A comparison of microtensile bond strengths of several dentin bonding systems to primary and permanent dentin. Dent Mater. 2002 May;18(3):239-45.

11. Hosoya Y, Nishiguchi M, Kashiwabara Y, Horiuchi A, Goto G. Comparison of two dentin adhesives to primary vs. permanent bovine dentin. J Clin Pediatr Dent. 1997 Fall;22(1):69-76.

12. Can-Karabulut DC, Oz FT, Karabulut B, Batmaz I, Ilk O. Adhesion to primary and permanent dentin and a simple model approach. Eur J Dent. 2009 Jan;3(1):32-41.

13. Bordin-Aykroyd S, Sefton J, Davies EH. In vitro bond strengths of three current dentin adhesives to primary and permanent teeth. Dent Mater. 1992 Mar;8(2):74-8.

14. Pashley DH, Tay FR, Yiu C, Hashimoto M, Breschi L, Carvalho RM, et al.. Collagen degradation by host-derived enzymes during aging. J Dent Res. 2004 Mar;83(3):216-21. 
15. Hashimoto M, Fujita S, Nagano F, Ohno H, Endo K. Tenyears degradation of resin-dentin bonds. Eur J Oral Sci. 2010 Aug;118(4):404-10.

16. Hashimoto $M$, Ohno $H$, Sano $H$, Kaga $M$, Oguchi $H$. In vitro degradation of resin-dentin bonds analyzed by microtensile bond test, scanning and transmission electron microscopy. Biomaterials. 2003 Sep;24(21):3795-803.

17. Liu Y, Tjaderhane L, Breschi L, Mazzoni A, Li N, Mao J, et al.. Limitations in bonding to dentin and experimental strategies to prevent bond degradation. J Dent Res. 2011 Aug;90(8):95368.

18. Marquezan M, Osorio R, Ciamponi AL, Toledano M. Resistance to degradation of bonded restorations to simulated caries affected primary dentin. Am J Dent. 2010 Feb;23(1):47-52.

19. Ricci HA, Sanabe ME, de Souza Costa CA, Pashley DH, Hebling J. Chlorhexidine increases the longevity of in vivo resin-dentin bonds. Eur J Oral Sci. 2010 Aug;118(4):411-6. Erratum in: Eur J Oral Sci. 2010 Oct;118(5):535.

20. Leitune VC, Portella FF, Bohn PV, Collares FM, Samuel SM. Influence of chlorhexidine application on longitudinal adhe- sive bond strength in deciduous teeth. Braz Oral Res. 2011 Sep-Oct;25(5):388-92.

21. Skovron L, Kogeo D, Gordillo LA, Meier MM, Gomes OM, Reis A, et al.. Effects of immersion time and frequency of water exchange on durability of etch-and-rinse adhesive. J Biomed Mater Res B Appl Biomater. 2010 Nov;95(2):339-46.

22. Sardella TN, de Castro FL, Sanabe ME, Hebling J. Shortening of primary dentin etching time and its implication on bond strength. J Dent. 2005 May;33(5):355-62.

23. Sanabe ME, Kantovitz KR, Costa CA, Hebling J. Effect of acid etching time on the degradation of resin-dentin bonds in primary teeth. Am J Dent. 2009 Feb;22(1):37-42.

24. Yiu CK, Hiraishi N, Tay FR, King NM. Effect of chlorhexidine incorporation into dental adhesive resin on durability of resin-dentin bond. J Adhes Dent. 2012 Apr 17. doi: 10.3290/j. jad.a25674. [Epub ahead of print].

25. Stanislawczuk R, Amaral RC, Zander-Grande C, Gagler D, Reis A, Loguercio AD. Chlorhexidine-containing acid conditioner preserves the longevity of resin-dentin bonds. Oper Dent. 2009 Jul-Aug;34(4):481-90. 